\title{
Review of Possible Mechanisms of Analgesic Effect of Herbs and Herbal Active Ingredient
}

\author{
Elahe Aleebrahim-Dehkordy ${ }^{1,2}$, Mohammad Reza Tamadon ${ }^{3}$, Hamid Nasri ${ }^{4}$, Azar Baradaran 5 , Parto Nasri ${ }^{5}$, Sara Beigrezaei ${ }^{6 *}$ \\ 'Researcher and Elite Club, Shahrekord Branch, Islamic Azad University, Shahrekord, IRAN. \\ 2Medical Plants Research Center, Shahrekord University of Medical Sciences, Shahrekord, IRAN. \\ 3Department of Internal Medicine, Semnan University of Medical Sciences, Semnan, IRAN. \\ ${ }^{4}$ Department of internal Medicine, Isfahan University of Medical Sciences, Isfahan, IRAN. \\ ${ }^{5}$ School of Medicine, Isfahan University of Medical Sciences, Isfahan, IRAN. \\ ${ }^{6}$ School of Nutrition \& Food Sciences, Isfahan University of Medical Sciences, Isfahan, IRAN.
}

\begin{abstract}
Pain is a distressing feeling caused by damage to different tissues. Consequently the person reacts, and tries to remove the painful stimulus. On the other hand, prostaglandins contribute to the emergence of pain. These compounds are formed and secreted by cyclogenase 2 or COX-2 enzymes. It is through inhibiting these enzymes that most of the analgesic medications act. Thus, this study aims to investigate and review some of the scientific findings on analgesic effects and possible active ingredients and analgesic mechanisms of these herbs. Result: Nowadays one of the methods to control pain is using non-steroid anti-inflammatory medications. Although the analgesic effects of these medications emerge relatively fast, but their side effects are considered to be a limiting factor in their usage. Therefore researchers are constantly in the search of new medications with less side effects. In recent years the tendency to use herbal medications has significantly increased in the treatment and prediction of these diseases. Since analgesic medications show a wide range of complications therefore using secondary herbal compounds may be an appropriate alternative for chemical medications. In this respect, many
\end{abstract}

analgesic effects of herbal medications have been brought into attention and it is believed that many natural compounds may serve as new medical compounds.Conclusion: Regarding the importance of research about pain and the effort in increasing awareness in this respect and also regarding the problems caused by using opioid medications, it is necessary to find herbal medications.

Key words: Analgesic effect, Possible mechanisms, Herbal medications, Herbal active ingredients.

\section{Correspondence:}

Sara Beigrezaei, School of Nutrition \& Food Science, Isfahan University of Medical Sciences, Isfahan, IRAN.

Email: s.beigrezaei93@yahoo.com

DOI: 10.5530/jyp.2017.9.60

\section{INTRODUCTION}

Pain emerges when a tissue is damaged. It causes the individual to react and try to get rid of the painful stimulus. It may be stated that pain comprises of three parts: sensory, emotional and affective. Illness, inflammation and damage to the central and the peripheral nervous system leads to significant changes in pain pathways, increase in excitability, and change in gene manifestations, enzymes and receptors. ${ }^{1}$ Prostaglandins also contribute to the induction of pain. These compounds have important inter-cell effects and may be released under specific physiological and pathological conditions into the blood flow. Prostaglandins are formed by an enzyme called cyclooxygenase 2 (COX-2). This enzyme is secreted by damaged cells and induces the feeling of pain through connecting to the receptors related to G-proteins and increasing CAMP amount in the cells. As suffering pains causes mental discomfort, humans have always sought a way to remove or decrease pain. ${ }^{2}$ Nowadays one of the ways to control pain is using non-steroid anti-inflammatory medications. Although their analgesic effect is induced relatively fast but this side effect is one of their limiting factors in using them. For instance these medications cause stomach dysfunction, dizziness, blurred vision, skin rash, pruritus and liver damage. ${ }^{1}$ Furthermore, non-steroid anti-inflammatory medications cost a lot of expense. Therefore researchers are looking for less expensive herbal medications and side less side effects; thus the analgesic effects of many medications have been investigated. Using herbal medications has been popular since antiquity. In the past decade, there also has been a significant rise in the usage of these medications among people. ${ }^{3}$ The increase in the resistance of pathogens toward chemical medications and also their side effects are one of the chief reasons for pharmaceutical companies, doctors and the public to adopt herbal medications for treatment. Therefore secondary ingredients in herbs may serve as good replacements for synthetic drugs. Finding and introducing herbs with medicinal properties such as analgesic properties is necessary and may lay the ground for the treatment of various disorders and complications and opens up new horizons for scientists and researchers. ${ }^{3}$ One of the many analgesic ingredients are flavonoids. Flavonoids are polyphenol ingredients that may cross the blood-brain barrier and modulate pain centrally through different mechanisms, such as affecting opioid GABA, alpha 2 adrenergic and inhibiting the enzymes involved in inflammation. ${ }^{4}$ Researches also show that flavonoids reduce intercellular calcium through inhibiting the activity of N-methyl-D-aspartate receptors and as a result inhibiting the activity of the enzyme, synthesizing nitric oxide and a2-phosphpolipease related to calcium and manifest its analgesic properties by decreasing NO and prostaglandins. For instance, flavonoids in tarragon decrease pain through their protective properties operating against oxidative stress caused by hyperglycemia and ingredients with similar properties to benzodiazepines. ${ }^{5}$ Regarding the importance of research about pain and the effort in raising awareness in this respect and also regarding the problems caused by using opioid medications, it

This is an open access article distributed under the terms of the Creative Commons Attribution-NonCommercial-ShareAlike 4.0 License, which allows others to remix, tweak, and build upon the work non-commercially, as long as the author is credited and the new creations are licensed under the identical terms. 
is necessary to try to find herbal medications. Thus, this study aims to investigate and review some of the scientific findings on analgesic effects and probable active ingredients and possible analgesic effect mechanisms of these herbs.

\section{METHODS}

For this review, we used a diversity of sources by searching through PubMed/Medline, Scopus, Web of sciences, EMBASE, EBSCO and directory of open access journals (DOAJ). The search was conducted, using combination of the following key words and or their equivalents: analgesic effect, possible mechanisms, herbal medications, herbal active ingredients.

\section{RESULT}

Analgesic effects of Medicinal plants and their active ingredients

Medicinal plants induce a biological equilibrium due to their natural active ingredients and their concomitance with other ingredients and prevent accumulation of medical substances in the body. Some of these abundant ingredients in herbs with analgesic properties are flavonoids. Flavonoids prevent the inducement of prostaglandins through inhibiting cyclooxygenase in the inflamed tissue. ${ }^{5}$ Flavonoids such as apigenin, reduce the accumulation of flowing lipids necessary for signaling pain. Therefore, flavonoids reduce inflammatory pain through inhibiting the receptors and the signaling cascade. ${ }^{5}$ From the many of the analgesic herbal ingredients, menthone, tannin and menthol may be mentioned. Studies show menthol has an exclusive receptor in the cell membrane which causes the resting flow toward the cell to reduce. It also increases the cellular stimulation threshold. This ingredient through affecting calcium channels in the nervous cell membranes, especially pain pathway neurons, reduces the inward calcium flow and reduces synaptic transmission and induces pain. ${ }^{6}$ In (Table 1 ) some of the most important herbs with analgesic properties have been mentioned along with their possible mechanisms. Herbal active ingredients reducing pain include flavonoids (Quercetin), volatile oils (monoterpenes and sesquiterpene). Phenol ingredients such as Thymol and Carvacrol, Coumarin, glycoside steroids, alkaloid ingredients, organic acids, tannins, Limonenes, Cineols and Saponins. ${ }^{3}$

The presence of flavonoid and iridoid compounds in siderites extract is responsible for analgesic effects and is the reason for its traditional use. Linalool is also one of the monoterpene ingredients in cinnamon that affect pain receptors and induce an analgesic effect. Phenols such as eugenol inhibit calcium from entering the cell and thus relieve pain.? Gingerol, an active ingredient in rhizome ginger, has a strong ability in inhibiting prostaglandins. And through mechanisms that reduce vascular permeability and production of pain mediators, is the chief analgesic agent of ginger. ${ }^{3}$ Analgesic effect of ziziphora clinopodioiedes from the Lamiaceae family has been attributed to pulegone that seems to do this through inhibiting acid arachidonic and prostaglandins synthesis and affecting opioids. ${ }^{1}$

\section{DISCUSSION}

\section{Glycyrrhiza glabra}

Glycyrrhiza glabra root (rhizome) includes glycerin which is 50 times more than sucrose. Its commercial extracts include glycyrrhizin in ammonium salt and G. glabra alcoholic extract which comprises of four active ingredients: glycaemia coumarin glycerin, hydro glia aspirin $\mathrm{C}$ and dehydrogol aspirin D. Other ingredients of this herb are flavonoids including Isoflavone, Liquiritin, iso liquiritin, formononetin, poly saccharides, esteroles, coumarines, asparagine, amino acids, resin, starch, oil essences, and saponins. ${ }^{8}$ This herb is a remedy for coughing, it hasmucolytic, anti-inflammatory and laxative properties and is used effectively to treat stomach and duodenum illnesses. ${ }^{9}$ It is also used in treating upper respiratory tract infections, bronchitis, peptic ulcers, duodenalulcers, chronic gastritis, rheumatism, arthritis, and adrenal

Table 1: Some of the medicinal plants with analgesic effects and their possible analgesic mechanisms

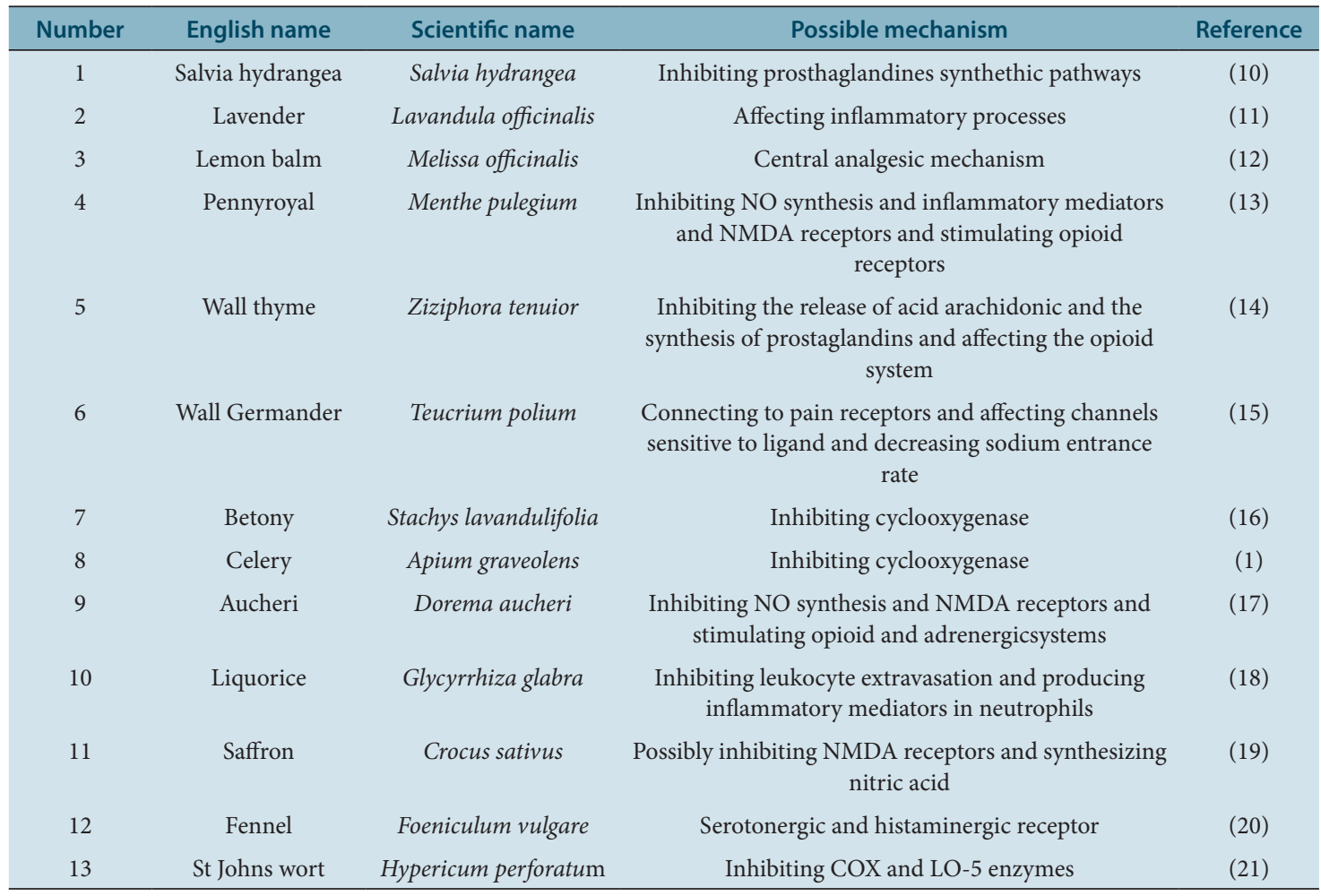


glandsfailure. Its products are widely used in pharmaceuticals as sweetener and as binder. Liquorice is useful in treating skincomplications such as dermatitis, eczema and pruritus. It has anti-infectious, anti-sceptic, anti-bacterial, anti hepatotoxity, anti-virus and antiphlogistic characteristics. Liquoricecauses antispasmodic effects in gastrointestinal tract and visceral pain relief through inhibiting phosphodiesterase 3. Its hydro alcoholic extract, through increasing defensive factors of gastric mucosa induces anti-ulcer mechanisms. ${ }^{8,9}$ Glycyrrhizinis another one of the liquoriceingredients. Its oral use inhibits 11- beta dehydrogenase enzyme and consequently increases the blood cortisol level. It is probable that this ingredient reduces pain through reducing inflammation. ${ }^{9}$

\section{Melissa officinalis}

Shoots contain great concentrations of its essence. The most important ingredients of Melissa officinalis essence arecitronella, citral, geraniol, ocimene, limonene, caryophyllene, linalool and other ingredients such as tannin, flavonoid and polyphenol. Its leaves contain aldehydemonoterpenoid, flavonoids (quercetin, luteolin), polyphenolic ingredients (rosemarinic acid, caffeic acid) and triterpenes. It also contains sesquiterpene and ingredients containing oxygen. ${ }^{22,23}$ M. officinalis is sedative, cardiactonic, memory and mental tonic. This herb is used for treating gastrointestinal, cardiovascular and neural illnesses and its ointment is antiherpes. It is also used for treating insomnia, sleeping disorders, anxiety, depression, neural illnesses, migraine, nausea, nervous stomach, anorexia, colic, cough, irregular menstruation, toothache and nervous tremors. Its lotion, obtained through brewing its herb, relieves pain if applied to scars and wounds. ${ }^{26}$ One of its most important analgesic effects has been attributed to limonene. Through reviewing the past studies on herbal extracts with analgesic effects, it may be concluded that it is probably limonene that is responsible for the analgesic and antiinflammatory properties of dracocephalum. This ingredient is present in celery essence, comprising more than 60 percent and in Anethum graveolens comprising about 32 percent of its volume. ${ }^{3}$

\section{Anethum graveolens}

The most important active ingredient in Anethum graveolens is d-carvone which is present in both its herb and its seed. Its fruit (seed) contains 102 to 7-7 percent essence, dylanoside (a xanthoneglycoside), coumarin, kaempferol, vicenin, myristicin and other flavonoids, phenol acids, protein and fat. The main flavenol glycoside in its leaves are quercetin, quercetin 3- o- beta di glucuronide and isorhamnetin 3-o-beta di glucuronide. ${ }^{24}$ This herb is used in traditional medicineas a body and stomach tonic, digestive, carminative, anti-convulsant, antiemetic and sedative. It is used to increase the secretion of mother's milk. A. graveolens has a plethora of biological benefits. It has appetizing, carminative, diuretic, anti-spasm, anti-jaundice, anti-cholesterol, anti-cancer and anti- oxidation properties. It reducesLDL and tri-glyceride and increases HDL. Limonene ingredients, carvone and kaempferol in dillhaveanalgesic and anti-inflammatory effects. Analgesic effects of carvone are achieved through affecting glutamate receptors, furthermore its analgesic activity may be through decreasing the neuropathy of the peripheral nerves. Kaempferol also has analgesic and anti-inflammatory effects. It acts by inhibiting cyclooxygenase 2 enzymes through suppressing SRC kinase. Limonene suppresses the activity of prostaglandins through inhibiting cyclooxygenase 1 and 2 enzymes and thus is effective in inhibiting pain and inflammation..$^{25,26}$

\section{Matricaria recutita}

The essence in Matricaria recutita blossoms includes Proazulenes, farnesene, alfa bisabolol, bisabolol oxide, spiroether, and flavonoids such as: anthemidin, luteolin, tannin, rutin and bitter glucosides, coumarines, mucilage substances and pectin compounds. ${ }^{27}$ This herb is used to decrease fever and sweating, relieving headache and migraine pains and arthrosis, menstrual period disorders and menopause, reducing blood pressure and relieving spinal column complications. It is ananti-infection, stomachanti-inflammation, appetizer and carminative. It is used in treating rhinorrhea and agitation. It is also used to treat hemorrhoid, eliminate wrinkles around eyes, moisturize skin and make hair shiny. ${ }^{27} \mathrm{M}$. recutita blossom contains some compounds like benzodiazepines and is proved to have analgesic properties. Researches have proved that the simultaneous injection of compounds present in chamomile blossom like flavonoid quercetin increases the tolerance to the analgesic effects of morphine. It also has been shown that flavonoid compounds of $M$. recutita blossoms act as CNS activator molecules. And have introducedthe flavonoidchrysene, as a partial agonist to benzodiazepine receptors. So far M. recutita blossoms has been used in treating skin inflammation, hemorrhoid, foot scars, urine burns in infants and in relieving pain and increasing the recovery rate of damaged tissues. ${ }^{28,29}$

\section{Lavandula officinalis}

The essence in Lavandula officinalis shoots contains flavonoid, tannin and coumarine. Its essence contains more than 40 compounds, the most important onesbeing linalool, linalyl acetate, cineol, nerol and borneol. Its other medical compounds are geraniol, alpha pinon, camphor, acid butyric, valeric acid, ursolic acid and luteolin flavonoids. L. officinalis root is a strong anticonvulsant and its leaves and blossoms are used to relieve pain. The essence of this herb has tranquilizing and anti-depression properties. It is also used for removing helminth, opening congestions, memory tonic, gout relief and rheumatism and also for relieving skin diseases such as eczema, acne, and burns and as a burn relief and insect sting relief. ${ }^{30}$ Linalool and linalyl acetate in L. officinalis shoots able to stimulate parasympathetic nervous system, and is efficient on relieving the painfollowing laparoscopic surgery. 1, 8 cineol are the most important active ingredient of this herb with analgesic properties. This ingredient may prevent the formation of prostaglandins such as PGE2 and leukotrienes such as LtB4, which are pain mediators, through inhibiting acid arachidonic metabolism. In clinical researches it has been proved that L. officinalis shoots essence may prevent the degranulation of host cells and the releasing of histamines. Ketones in lavender may efficiently reduce inflammation and improve sleeping. ${ }^{31}$

\section{CONCLUSION}

Medicinal plants may establish a biological equilibrium and prevent the accumulation of medical ingredients due to their active ingredients. Having low complications or not having it at all, is their considerable advantage over the chemical medications. The most important herbal ingredients with analgesic effect include flavonoids, volatile oils. Phenol compounds, alkaloid compounds, organic acids and essence. These compounds prevent the formation of cyclooxygenase enzyme and consequently prevent the formation of prostaglandins. Regarding the priority of pain relief for patients, it is necessary to increase the awareness in order to deal with harmful bodily and mental effects of pain. And one of the possible solutions for obtaining analgesic medications is further investigating medical herbs and natural compounds.

\section{REFERENCES}

1. Ghahhari J, Vaezi G, Shariatifar N, Zendehdel Kh M. The study of hydroalcoholic extract of Ziziphora tenuior on visceral pain with writhing test in mice. The Horizon of Medical Sciences. 2009;15(2):24-9.

2. Ardalan MR, Rafieian-Kopaei M. Is the safety of herbal medicines for kidneys under question?. Journal of Nephropharmacology.2013;2(2):11. PMid:28197435 PMCid:PMC5297543

3. Pandey R, Tiwari RK, Shukla SS. Omics: A Newer Technique in Herbal Drug Standardization \& Quantification. Journal of Young Pharmacists. 2016;8(2):76. https://doi.org/10.5530/jyp.2016.2.4.

4. Dwevedi A, Dwivedi R, Sharma YK. Exploration of phytochemicals found in Terminalia sp. and their antiretroviral activities. Pharmacognosy Reviews. 
2016;10(20):73. https://doi.org/10.4103/0973-7847.194048; PMid:28082788 PMCid:PMC5214561.

5. David AV, Arulmoli R, Parasuraman S. Overviews of biological importance of quercetin: A bioactive flavonoid. Pharmacognosy Reviews. 2016;10(20):84. https:// doi.org/10.4103/0973-7847.194044; PMid:28082789 PMCid:PMC5214562.

6. Tavafi M, Sameni HR, Tamjidipour A, Hasanvand A, Ashoory H. Antioxidant effect of rosmarinic acid against renal ischemia reperfusion injury in rat; a histopathological study. Annals of Research in Antioxidants. 2016;1(2).

7. Dashti-Rahmatabadi M, Vahidi Merjardi A, Pilavaran A, Farzan F.Antinociceptive Effect of Cinnamon Extract on Formalin Induced Pain in Rat. JSSU.2009;17: 190-199.

8. Montoro P, Maldini M, Russo M, Postorino S, Piacente S, Pizza C. Metabolic profiling of roots of liquorice (Glycyrrhiza glabra) from different geographica areas by ESI/MS/MS and determination of major metabolites by LC-ESI/ MS and LC-ESI/MS/MS. Journal of pharmaceutical and biomedical analysis. 2011;54(3):535-44. https://doi.org/10.1016/j.jpba.2010.10.004; PMid:21041055.

9. Isah T. Anticancer alkaloids from trees: Development into drugs. Pharmacognosy Reviews. 2016;10(20):90. https://doi.org/10.4103/0973-7847.194047 PMid:28082790 PMCid:PMC5214563.

10. Sonboli A, Kanani M, Yousefzadi M, Mojarad M. Chemical Composition and Antibacterial Activity of the Essential Oil of Salvia hydrangea from Two Localities of Iran. JMP.2009; 2:20-28.

11. Heidari MR, Zahedi MJ, Rezvani H. Analgesic effect of lavandula officinalis and histopatological studies in mice.

12. MILADI GH, RASHIDIPOUR A, Vafaei AA, TAHERIAN AA. Opioid receptors role on anti-nociceptive effects of the aqueous extracts of Melissa officinalis in mice.

13. Mokhtari M, Shariati M, L Khodaparast. The antinociceptive effect of hydroalcoholic extract of leave Mentha pulegium in formalin test in male rat. J Shahrekord Univ Med Sci.2009;40: 12-7.

14. Shahraki MH, MirShekari H, J Palan M. The comparison of nociceptive effect of Teucrium polium and morphine in female rats. The Horizon of Medical Sciences. 2006;12(1):10-4

15. Nasri S, Ramezanghorbani A, Kamalinejad M. Analgesic and anti-inflammatory effects of hydroalcoholic extract of Stachys Lavandulifolia Vahl s, aerial parts in male mice. Armaghane danesh. 2011;16(2):161-71.

16. Nasri S, Ramazani M, Yasa N. Antinociceptive and anti-inflammatory effects of hydro-alcoholic extract of Apium graveolens. J Shahrekord Univ Med Sci.2009; (4) :25-31

17. Mokhtari M, Shariati M, Niknam H. The Effect of Antinociceptive and Antiinflammatory of Hydro -Alcohol Extract of Dorema aucheri on FormalinTest and Carrageenan Model in Rats. J Rafsenjan Univ of Med.2008;7:165-72.

18. Zareian P, Esmaeili Mahani S, Taherianfard M. The effect of licorice root extract on acute and chronic pain. J Med Fac. 2003;10:851-7.

19. Zardooz H, Shams J, Izadi H.R, Ghoshooni H, Arbabian S, Kamalinejad M, et al.
Effect of water extract of saffron (Crocus sativus) on chronic phase of formaline test in female mice. Kowsar J.2009; 14:11-8.

20. Taherian A, Dehghanina M, Vafaei A, Sadeghi H, Miladi Gorgi H. Effects of aqueous extract of fruit of Foeniculum vulgar on neurogenic and inflamatory pain in mice. SJKU. 2007;12:29-36.

21. Khaksarian M, Javan M, Sonboli A, Motamedi F. Inhibition of acute and chronic pain in male rats by aqueous extract of Hypericum perforatum $L$.

22. Nasri H. Herbal drugs and new concepts on its use. Journal of Preventive Epidemiology. 2016;1(1).

23. Guginski G, Luiz AP, Silva MD, Massaro M, Martins DF, et al. Mechanisms involved in the antinociception caused by ethanolic extract obtained from the leaves of Melissa officinalis (lemon balm) in mice. Pharmacology Biochemistry and Behavior. 2009;93(1):10-6. https://doi.org/10.1016/j.pbb.2009.03.014; PMid:19358864.

24. Namjoo AR, MirVakili M, RAFIEIAN KM, Faghani M. Histopatological and biochemical effects of subcute toxicity of lemon balm hydroalcoholic extract on liver and kidney tissues in the surri mice.

25. Hosseinzadeh H, Karimi G, Ameri M. Effects of Anethum graveolens L. seed extracts on experimental gastric irritation models in mice. BMC pharmacology. 2002;2(1):21. https://doi.org/10.1186/1471-2210-2-7; https://doi.org/10.1186/14712210-2-21; PMid:12493079 PMCid:PMC140031

26. Cheraghi J, Valadi A. The analgesic and anti-inflammatory effect of limonene compounds found in medicinal plants. Med Aromatic Plants Res J.2005; 3: 415-22.

27. Lee KM, Lee KW, Jung SK, Lee EJ, Heo YS, Bode AM, Lubet RA, Lee HJ, Dong Z. Kaempferol inhibits UVB-induced COX-2 expression by suppressing Src kinase activity. Biochemical pharmacology. 2010;80(12):2042-9. https://doi. org/10.1016/j.bcp.2010.06.042; PMid:20599768 PMCid:PMC2974004.

28. Gomaa A, Hashem T, Mohamed M, Ashry E. Matricaria chamomilla extract inhibits both development of morphine dependence and expression of abstinence syndrome in rats. Journal of pharmacological sciences. 2003;92(1):50-5 https://doi.org/10.1254/jphs.92.50; PMid:12832855.

29. Jarrahi M, Khorasani M,Taherian AA, Meladi H, Safakhah HA.Effect of topical chamomile oil extracts the shear cutaneous wound healing in rats. J Med Plants Semnan .2008;1:94-9.

30. Martins MD, Marques MM, Bussadori SK, Martins MA, Pavesi VC, MesquitaFerrari RA, Fernandes KP. Comparative analysis between Chamomilla recutita and corticosteroids on wound healing. An in vitro and in vivo study. Phytotherapy Research. 2009;23(2):274-8.https://doi.org/10.1002/ptr.2612; PMid:18803230.

31. Hajhashemi V, Ghannadi A, Sharif B. Anti-inflammatory and analgesic properties of the leaf extracts and essential oil of Lavandula angustifolia Mill. Journal of ethnopharmacology. 2003;89(1):67-71. https://doi.org/10.1016/S0378-8741 (03)00234-4.

32. Zamanian-Azodi M, Rezaie-Tavirani M, Heydari-Kashal S, Kalantari S, Dailian S, Zali $\mathrm{H}$. Proteomics analysis of MKN45 cell line before and after treatment with Lavender aqueous extract. Gastroenterol Hepatol bed bench. 2011;5:1-8.

Article History: Submission Date : 17-01-2017; Revised Date : xx-xx-xxx; Acceptance Date : 16-04-2017.

Cite this article: Dehkordy EA, Tamadon MR, Nasri H, Baradaran A, Nasri P, Beigrezaei S. Review of Possible Mechanisms of Analgesic Effect of Herbs and Herbal Active Ingredient. J Young Pharm. 2017;9(3):303-6. 